Western University

Scholarship@Western

Aboriginal Policy Research Consortium International (APRCi)

2012

\title{
Decolonizing Indigenous disability in Australia
}

David Hollinsworth

University of the Sunshine Coast

Follow this and additional works at: https://ir.lib.uwo.ca/aprci

Part of the Other Sociology Commons

Citation of this paper:

Hollinsworth, David, "Decolonizing Indigenous disability in Australia" (2012). Aboriginal Policy Research Consortium International (APRCi). 403.

https://ir.lib.uwo.ca/aprci/403 
This article was downloaded by: [University of Western Ontario]

On: 18 November 2012, At: 06:52

Publisher: Routledge

Informa Ltd Registered in England and Wales Registered Number: 1072954 Registered

office: Mortimer House, 37-41 Mortimer Street, London W1T 3J H, UK

\section{Disability \& Society}

Publication details, including instructions for authors and subscription information:

http:// www.tandfonline.com/loi/ cdso20

\section{Decolonizing Indigenous disability in Australia}

David Hollinsworth ${ }^{a}$

a University of the Sunshine Coast, School of Social Sciences, Maroochydore DC, Australia

Version of record first published: 12 Sep 2012.

To cite this article: David Hollinsworth (2012): Decolonizing Indigenous disability in Australia, Disability \& Society, DOI: 10.1080/ 09687599.2012.717879

To link to this article: http:// dx.doi.org/ 10.1080/ 09687599.2012.717879

\section{OFirst}

\section{PLEASE SCROLL DOWN FOR ARTICLE}

Full terms and conditions of use: http://www.tandfonline.com/page/terms-andconditions

This article may be used for research, teaching, and private study purposes. Any substantial or systematic reproduction, redistribution, reselling, loan, sub-licensing, systematic supply, or distribution in any form to anyone is expressly forbidden.

The publisher does not give any warranty express or implied or make any representation that the contents will be complete or accurate or up to date. The accuracy of any instructions, formulae, and drug doses should be independently verified with primary sources. The publisher shall not be liable for any loss, actions, claims, proceedings, demand, or costs or damages whatsoever or howsoever caused arising directly or indirectly in connection with or arising out of the use of this material. 


\title{
Decolonizing Indigenous disability in Australia
}

\author{
David Hollinsworth* \\ University of the Sunshine Coast, School of Social Sciences, Maroochydore DC, Australia \\ (Received 5 December 2011; final version received 12 July 2012)
}

\begin{abstract}
Cultural diversity and social inequality are often ignored or downplayed in disability services. Where they are recognized, racial and cultural differences are often essentialized, ignoring diversity within minority groups and intersectionality with other forms of oppression. This is often an issue for Indigenous Australians living with disability. This paper argues that understanding Indigenous disability in Australia requires a critical examination of the history of racism that has systematically disabled most Indigenous people across generations and continues to cause disproportionate rates of impairment. Approaches that focus on the cultural 'otherness' of Indigenous people and fail to address taken-for-granted normative 'whiteness' and institutional and discursive racism are unable to escape that history.
\end{abstract}

Keywords: racism; Indigenous Australians; eugenics; decolonizing

\section{Points of interest}

- Colonialism and racism in Australia has 'disabled' Indigenous people over many generations regardless of their physical or mental impairment.

- Racism towards Indigenous Australians results in rates of impairment two or three times higher than the national average.

- Poverty, marginalization and racism can mean that many Indigenous Australians do not see impairment as a disability but as an aspect of more general challenges and disadvantage.

- Disability services must recognize the history and ongoing impact of this racism and incorporate that awareness into their practice.

- More research is needed to understand Indigenous experiences of impairment and disability, and implications for disability studies generally.

\section{Introduction}

Raewyn Connell calls for a critical disability studies informed by Southern perspectives that place impairment 'in the context of the violence of colonisation and neocolonial power' $(2011,1369)$. Within this perspective, 'both disability and impairment are regarded as important dimensions of lived experience' (Connell 2011, 1370). Helen Meekosha (2006, 2011; Meekosha and Dowse 1997) has argued for a critical recognition of the intersectionality of race, gender, disability 
and citizenship. In particular, Southern challenges to the north Atlantic view of disability as socially constructed in opposition to the medical model have highlighted the often problematic nature of the state especially in relation to Indigenous people. Meekosha and Soldatic conclude that:

While Northern discourses promote an examination of disabled bodies in social dynamics, we argue that the politics of impairment in the global South must understand social dynamics in bodies. $(2011,1381)$

This emerging Southern approach emphasizes global imperial power relations, and military and economic entanglements. This paper provides a critical examination of the historical roots and intergenerational impacts of colonialism on Indigenous Australians living with impairment. It argues that racism and discourses of Indigenous inferiority and dysfunction are disabling for all Indigenous Australians regardless of impairment. Additionally poverty, colonization and their intergenerational impacts continue to create massively disproportionate impairment among Indigenous Australians. It therefore contends that struggles for the rights of disabled Indigenous people require both anti-racism (including acknowledgement of the history of racism and colonialism towards Indigenous people generally) and efforts to combat the causes and counter the impacts of impairments created by ongoing racism and colonialism.

There are many striking parallels between the attitudes towards and treatment of Australians with disabilities and Indigenous Australians irrespective of dis/ability. Yet most studies of disability ignore cultural diversity, while much cultural theory excludes consideration of bodily capacity (Jakubowicz and Meekosha 2002; Meekosha 2006; Soldatic and Fiske 2009). Where Indigenous people with disabilities are acknowledged, the models are often simplistically cumulative, with Aboriginality and disability being added together to constitute a 'double disadvantage' (Gething 1994, 14).

\section{Acknowledging history}

Jakubowicz and Meekosha $(2002,246)$ note that the presence of disabled people 'is always noticed, or manifestly not noticed'. A parallel hypervisibility or invisibility of Aboriginality occurs in disability studies and programmes. Health professionals typically fail to acknowledge context and historical differences for Indigenous clients or become preoccupied and frozen by their awareness of Aboriginality (Kowal 2011). Differences flowing from history continue to mark Indigenous people as 'other' or the object of pity or shame. The particular and diverse experiences of Indigenous people with disabilities remain occluded within disability studies and policy debates.

The principal recommendation of Family Dreaming, the 1998 report on Support Programs for Aboriginal and Torres Strait Islander people with disabilities, states:

The development of support services for Aboriginal and Torres Strait Islander people with a disability must take into account the implications of the traumatic history of indigenous people since first contact. (Smeaton 1998, 1)

This article demonstrates why attempts to provide effective support services in the absence of such historical awareness and critical reflection of its ongoing implications will not succeed. That history continues to reverberate through the lives of 
Indigenous Australians, accounting for their patterns of ill-health and impairment, as well as shaping relations with the state and mainstream service providers. It is not possible to extricate Indigenous experiences of 'having a disability' from the often disabling experiences of being Indigenous in 'white' Australia. In a similar fashion, Salmon argues that Canadian Aboriginal mothers of babies with foetal alcohol syndrome are likewise positioned as 'outside' membership of the nation-state and 'transmitters of physical, moral, and cultural contagion' (2004, 112 and 114).

The history of Australia's treatment of Indigenous peoples provides important insights into these parallels as well as demonstrating why disability studies must attend to 'race', culture, and gender. Australian racism has been fundamental in terms of its impact on the rates of, recognition of, and responses to, impairment amongst Indigenous people. Racism, along with ableism, has effectively disabled an entire category of Australians since colonization.

This overview will canvas some disabling effects of racism and the historical treatment of Indigenous Australians as unfit for participation in nation-building. Factors leading to higher than average rates of impairment amongst Indigenous people are examined. This history of racism has been embedded in largely unacknowledged ways within institutional structures and processes and within discourses of Indigenous dysfunction that continue to disable Indigenous Australians. It is argued that without an awareness of such factors and histories it is impossible to provide appropriate or effective services to disabled Indigenous people today.

\section{Dispossession and dehumanization}

Following the arrival of the British in 1788, Indigenous Australians were progressively dispossessed of their lands and denied legal recognition as traditional owners or British subjects. Those who resisted were killed, although most died from starvation and introduced diseases such as smallpox, measles and influenza against which they had no immunity (Kunitz 1994). While many worked for rations on pastoral stations or did domestic work, Indigenous people were often regarded as scarcely human and incapable of becoming full members of the emerging nation.

Such dehumanizing attitudes were strengthened by the ideas of social Darwinism that bolstered notions of Indigenous incapacity and predicted their inevitable extinction in the face of superior, civilized Europeans (McGregor 1997). These racist beliefs not only denied Indigenous people's humanity, they condoned those who violently hurried on the inevitable (Rowley 1970). In Australia, social Darwinism provided a coherent theory that was believed to scientifically prove two beliefs widely held by the settler population of the nineteenth century: firstly, that Aborigines were biologically inferior; and secondly, that this inferiority was so profound as to condemn them to extinction in accordance with the laws of natural selection. This confidence in the supplanting of Indigenous types with the robust and superior introduced types became unquestioned common-sense accepted by authorities and publics alike (Anderson 2002). Indigenous Australians were frequently presented as uniquely able to demonstrate evolution, being examples of the lowest rung of development. Australia was seen as cut-off from the rest of the world: unchanging, primeval, a treasure-trove of archaic curiosities. This view persisted well into the twentieth century and accounts for the international preoccupation with the anatomy and mentality of Indigenous Australians (Goodwin 1964). 


\section{Protection, segregation and institutionalization}

By the end of the nineteenth century, many Indigenous people were rounded up and incarcerated on reserves and missions that were completely cut-off from 'white' society apart from their overseers (Brock 1993). The legislation that established these institutions also systematically removed all civil rights, including the rights to enter work contracts, receive wages, own land or other property, swear oaths or vote, reside or associate with non-Indigenous people, attend schools or hospitals (Hollinsworth 2006).

Government officials, called Protectors, assumed the guardianship of all children and adolescents regardless of their parents, and could split families at will (Haebich 2000). The threat of having the family broken up hung over many Indigenous families across several generations. Parents felt powerless to protect their children from abuse, especially when they were placed outside the institutions for work as adolescents. Some families were able to abscond from reserves and missions but remained fearful of detection and re-incarceration. Others 'passed' as Indian or of some other non-Indigenous ancestry.

The Protection legislation was grounded in powerful notions of moral, physical and racial threat to the integrity and security of the 'white race' and the nation; effectively seen as synonymous until the 1950s. In much the same way that restrictive immigration and medical quarantine laws and structures co-evolved, there were dual responsibilities and regulations for the control of Indigenous people and of contagious diseases such as leprosy, sexually transmitted diseases, yaws and respiratory diseases (Bashford and Nugent 2001).

Indigenous historian, Gordon Briscoe (2003) argues that disease was fundamental to Indigenous policy in the period 1900-1940. Regulations prohibiting consorting between Indigenous and non-Indigenous people blurred the dangers of moral corruption, miscegenation, 'plagues' and other forms of contagion (Evans 1976). Indigenous people suffering venereal diseases, leprosy, and tuberculosis were permanently detained in lock hospitals (Davidson 1978; Eckermann 2000; Jebb 1984; Hunter 1993). These facilities were located hundreds of kilometres away from 'white' towns, often on islands. While such isolation protected and reassured the general public, their location ensured that medical visits were rare and living conditions pitiful (Briscoe 2003, 122-126).

The threat of such diseases, and of less serious conditions such as parasitic worms, head lice, and gastroenteritis, was used to justify extraordinary surveillance and intrusions into the daily lives of Indigenous people. Homes and children could be inspected daily, nursing mothers were supervised, babies and small children were removed into locked and gender-segregated dormitories. Children were prevented from attending state schools, families were banned from residential areas, and facilities such as swimming pools and cinemas were segregated. Hospitals were usually segregated if they admitted Indigenous patients at all, with special wards on verandahs or in tents outside (Briscoe 2003, 142-151).

While contagious diseases were often used to justify the exclusion of Indigenous children from state schools, the official view was that Indigenous mental capacity made education beyond Year Three pointless in any case. Western Australian State Psychologist Ethel Stoneman argued in 1935 that 'only in exceptional circumstances' could Aboriginal children proceed beyond Year Four because 'of the poor physical condition of the black children and because of the fact that a large propor- 
tion of them were dull' (cited in Beresford and Omaji 1996, 53). Racism and social Darwinism marginalized and disabled all Indigenous Australians while their segregated oppression encouraged disease and impairment that reinforced their exclusion from the developing state.

\section{Breeding out the colour: eugenics and nation-building}

While it was widely believed that their inherent inferiority condemned Indigenous Australians to extinction, by the early twentieth century the growth in so-called 'half-caste' children alarmed those charged with policing the body politic (McGregor 1997). The Commonwealth government was holding Royal Commissions into the threat posed by the 'fact' that middle-class, 'white' women were refusing pregnancy while immoral and 'feebleminded' women bred indiscriminately. In such a context, the alleged hyper-fertility of 'mixed-race' people was terrifying to those committed to a healthy, wholesome White Australia. While Immigration restrictions could in theory exclude 'non-whites' from entry, what was to be done about the internal 'Half-caste Problem'?

A dying race could be nicely institutionalised and allowed to fade away; but what had this ['mixed race'] group of people to do in White Australia? (Rowley 1970, 139)

One strategy was institutionalization in segregated reserves but this approach failed to prevent 'uncontrolled interbreeding' on reserves. Many Indigenous girls indentured out as workers were raped and became pregnant to 'white' men. In northern Australia, 'white' men's lust was thought to be the undoing of the 'race' when confronted by the allegedly unbridled sexuality of Indigenous women. Dr Cecil Cook, Chief Medical Officer and Chief Protector of Aborigines in the Northern Territory between 1927 and 1939, believed the 'preponderance of coloured races, the prominence of alien coloured blood and the scarcity of white females ... creates a position of incalculable future menace to purity of race in tropical Australia' (quoted in Haebich 2000, 274). According to these racial gatekeepers, the state had to intervene to control the sexuality of Indigenous women and girls. It was literally inconceivable that 'white' women would marry or willingly mate with 'black' men so the policy largely ignored the reproductive fate of 'full-blood' or 'half-caste' men.

Cook's medical background may have predisposed him to eugenist methods and objectives. In 1933 Cook inquired of the government whether he could order the sterilization of 'half-caste' children classified as 'congenital idiots' or otherwise 'mentally defective' (McGregor 1997, 161). Presumably he was dissuaded, but this example highlights the international parallels between social Darwinist discourses of Indigenous inferiority and the eugenics movements' treatment of people with impairments (Groce and Marks 2000).

There have been many individual incidents of such medical authoritarianism. Recent examples include the use without consent of Depo Provera as a long-term contraceptive for Indigenous adolescents, and tubal ligation during caesarean sections for Indigenous mothers deemed to have had too many children. Apparently such crude eugenist interventions never became policy, although there was considerable opposition to fertility control programmes from Indigenous women well aware of the racial character of historical concern with Indigenous birth-rates (MoretonRobinson 2000, 171). 
However, as McGregor (2000) argues, eugenics can incorporate more than the elimination of the unfit and reproductive selection for racial improvement. It can take the form of 'constructive miscegenation' (Stepan 1991) designed to bolster the unity and integrity of the national 'imagined community' (Anderson 1991). By the mid-1930s the eugenic project was shifting from the prevention of breeding by those considered unfit to the manipulation of breeding for those with better potential on account of their 'white' blood. For Cook in particular, the biological absorption of 'half-castes' was the 'only method by which the future of this country can be safeguarded in the absence of such radical methods as sterilization of the unfit and legalized abortion' (quoted in McGregor 1997, 162).

Paradoxically, support for inter-racial breeding was based on an awareness of strong antipathy to Indigenous people. By preventing interbreeding with the 'dark', over several generations the colour that provoked this hostility could be bred out completely (Anderson 2002). Cook reassured the nation that:

Generally by the fifth and invariably by the sixth generation, all native characteristics of the Australian aborigine [sic] are eradicated. The problem of our half-castes will quickly be eliminated by the complete disappearance of the black race, and the swift submergence of their progeny in the white ... The Australian native is the most easily assimilated race on earth, physically and mentally. (Quoted in Markus 1990, 93)

This process of remaking the Indigenous body according to racial categorizations and genetic engineering was endorsed at the 1937 conference of Commonwealth and State Ministers of Native Affairs that resolved that 'the destiny of the natives of aboriginal origin, but not of the full blood, lies in their ultimate absorption by the people of the Commonwealth and it therefore recommends that all efforts be directed to that end' (Commonwealth Government 1937, 14). Such eugenic absolutism is chilling and reminds us of the interconnections between racism, eugenics and ableism for most of the twentieth century, and the extent to which control of reproduction and of children have been central to both Indigenous policy and disability.

\section{The stolen generations}

The most devastating of these efforts to secure the integrity of the nation through the eradication of colour was the removal of thousands of Indigenous children from their families (Human Rights and Equal Opportunity Commission [HREOC] 1997). Often children were seen as more redeemable than adults. In 1839 Matthew Moorhouse, Chief Protector in South Australia, declared:

Our chief hope is now decidedly in the children; and the complete success as far as regards their education and civilisation would be before us, if it were possible to remove them from the influence of their parents. (Cited in Rowley 1970, 103)

Under the Protection legislation outlined above, children could be legally detained or separated from their families usually without the authorities having to prove neglect or satisfy other child welfare laws. Under the Assimilation policies that replaced Protection in the 1950s and 1960s, removal of children to break the debilitating influence of the family was often intensified although increasingly using mainstream child protection legislation (HREOC 1997). 
Some of those removed went to special Indigenous Children's Homes. Some who were 'practically white' or suffering physical disabilities were placed in mainstream facilities and their Aboriginality denied. Others were fostered or adopted. From 1900 to 1970 , between one in 10 and one in three Indigenous children were forcibly removed by various authorities (HREOC 1997, 37). Those removed are now known as the Stolen Generations.

In 1996/97 the HREOC conducted a National Inquiry into the Separation of Aboriginal and Torres Strait Islander children from their families. The Inquiry heard evidence or received submissions from 777 people or organizations including 535 Indigenous people directly affected. Among the key findings were the brutal treatment many children received, the prevention of contact with their families or with other removed siblings, the training to fear or despise other Indigenous people, the excessive rates of physical, sexual and emotional abuse, and the failure to provide the education and other benefits that were used to justify the removal process (HREOC 1997).

One striking effect of removals for many children was the loss of primary carers and the consequent inability to learn good parenting in the institutions or while being fostered. These effects are often inter-generational with the children of those removed being themselves removed or not receiving confident and stable parental care. Parents reported being unable to show affection or to discipline children. In many cases, all forms of authority - especially child protection and welfare services - are feared (Cox 2007). This often results in non-presentation until a crisis, and non-compliance with instructions including follow-up appointments. Such behaviours frequently reinforce negative opinions amongst health professionals (Humphery, Weeramanthri, with Fritz 2001).

The inter-generational impact of such trauma is seen in the high rates of substance misuse, depression and mental illness, violence and self-harm, imprisonment and inability to form relationships experienced by many of those removed and their children and grandchildren (Ministerial Council for ATSI Affairs 2006). This historical pattern of government intervention, grief and trauma is fundamental to an informed assessment of impairment and disability among Indigenous Australians today (Nelson 2009).

Gradually, decades of discrimination and separatist guardianship gave way to assimilation policies of training and incorporation: yet discourses of deficit and dysfunction persisted. Indigenous families were expected to leave their institutions and merge with the mainstream, a process of de-institutionalization similar to that occurring with many non-Indigenous people with disabilities (Cocks and Stehlik 1996; Goggin and Newell 2005). Many Indigenous people resisted assimilation while still wishing to get access to better services and opportunities. Demands for Indigenousspecific health services were common, but often lacked expertise in disability (Smeaton 1998). In 2002 the Aboriginal Disability Network NSW was established to advocate for Indigenous people with disability in New South Wales (Aboriginal Disability Network NSW n.d.). In 2012 the federal government established the First People's Disability Network to advise on policies affecting the $37 \%$ of Indigenous Australians over 15 years living with disability (Griffis 2012).

\section{Disabled by the state: impairment creation in Indigenous Australia}

Racist representations of Indigenous people and their consequent treatment disabled virtually all Indigenous Australians, regardless of any specific impairment. The 
history of policies and practices towards Indigenous people has largely been one of neglect and exclusion, although some periods reveal intense surveillance, incarceration 'for their own good', medicalization including the pathologizing of Indigenous cultures, lifestyles and bodies, and eugenics through sterilization or more often control of sexuality. In some cases the same scientists and physicians used the very institutions that had catered for those deemed 'feeble-minded', epileptics or those with contagious disease, to detain and train Indigenous people, or vice versa (Evans 1976). This history includes the impacts of colonial violence and neo-colonial power that imposed widespread impairments alongside disabling discourses of moral and physical inferiority (Meekosha 2011). Meekosha and Soldatic (2011) argue that this 'Southern' experience challenges the dominant social model of disability and disability movements especially when the state remains a disabling force rather than defender of human rights. Equally, the social model does not acknowledge instances when poverty between and within nations maintains gross overburdens of impairment.

Some diseases, including blindness due to trachoma and diabetes, hearing loss, heart disease, leprosy, tuberculosis, and sexually transmitted diseases (Briscoe 2003), occurred frequently amongst Indigenous communities lacking basic housing and health infrastructure or access to health services. Generations of Indigenous people suffered from near starvation and poor nutrition, leading to disastrous effects in physical and intellectual development as well as heightened susceptibility to a myriad of diseases and disabilities. Malnutrition persists in remote communities, compounding other social determinants of chronic ill-health (Martin 2011).

Indigenous people were often terrified of government medical officers who would remove them (sometimes in neck-chains) to leprosariums and other locked institutions never to see their families again. Some children were placed in mainstream facilities based on their disability, including many polio victims (Ariotti 1999; Graham 2006). Indigenous people were often crippled at work on pastoral stations but received no treatment or compensation. In the 1950s Indigenous people in South Australia were contaminated by British nuclear tests, resulting in blindness and increased cancer rates (Lester 2000). Other Indigenous communities were blighted by being located next to asbestos mines, rubbish dumps and in flood-prone areas. These examples of state-created impairment emphasize the key role that institutional racism has in the production of disability for Indigenous Australians.

More generally, the ongoing effects of trauma and grief reverberate down through the generations for many Indigenous families. Particular issues include life expectancy more than 20 years less than other Australians, mental health issues, type 2 diabetes, heart disease, drug and alcohol misuse, family violence, self-harm and suicide (Productivity Commission 2011).

Indigenous people have stressed the impact of preventable impairment resulting from poor nutrition, maternal health, drug and alcohol misuse, accidents and injuries (Danelutti 2000). Some excess incidence of impairment among Indigenous people is caused by injurious behaviours including during pregnancy (cf. Salmon 2007). These effects are magnified by the general failure of health-promotion strategies directed at smoking, alcohol and drug misuse, exercise and nutrition.

However, there are many complex factors to consider in relation to preventable impairment. One crucial element is the general reluctance to seek medical attention, which frequently results in untreated chronic conditions that cause, or predispose Indigenous people to experience, serious permanent consequences (Devitt and 
McMasters 1998). Examples include type 2 diabetes, which leads to blindness, amputation and loss of mobility, and chronic infections resulting in renal failure requiring dialysis or in deafness due to otitis media. Other patterns reveal complex combinations of obesity, infection and poor nutrition leading to severe high blood pressure with attendant strokes, heart failure and other debilitating conditions (Australian Health Ministers' Advisory Council 2011). Again we observe 'social dynamics in bodies' (Meekosha and Soldatic 2011, 1381).

The struggle to extricate disability from a strictly medical paradigm is important for many disability advocacy groups. However, this approach may be inappropriate for Indigenous communities whose overall health and living conditions are so comprehensively inadequate (Ariotti 1999; Salmon 2007). In such circumstances, primary healthcare approaches and social justice issues are central to an effective person-centred engagement with disability (Hasnain, Sotnik, and Ghiloni 2003). A further consideration is the widespread antipathy to child-protection services and welfare agencies, often the administrative location for disability services (Smeaton 1998, 17-18).

One example of such interconnections is the vast over-representation of Indigenous people in the criminal justice system. Indigenous people are 14.2 times more likely to be in custody than other Australians; Indigenous youth are 22.7 times more likely to be in custody (Productivity Commission 2011). Many of all those in Australian prisons have severe mental disabilities, especially as there are now so few institutional beds available (Holland and Persson 2011). Drug use, violence and self-harm are endemic in prison. Institutional racism among police and in the courts combines with undetected and untreated illness to produce extremely high rates of disability, which is often concealed by a discourse of criminality and punishment (Australian Human Rights Commission 2008).

\section{Indigenous meanings of disability}

Most disability service providers have not yet addressed the implications of this history of government-imposed disablement on the programmes and services they offer to Indigenous people (Smeaton 1998; Danuletti 2000; Nelson 2009).

Available research indicates that the prevalence of impairment among Indigenous people is twice that of other Australians (Productivity Commission 2011). There is evidence of serious underestimation of Indigenous impairment rates, although this is reducing (Productivity Commission 2011, 4.85). This is due to massive underestimation in self-assessment by Indigenous people (Senior 2000). Disabilities among the 'elderly' (for Indigenous people, those over 50 years old) are usually regarded as part and parcel of ageing rather than a specific condition. Severe loss of hearing and intellectual disability as assessed by non-Indigenous practitioners are often not considered abnormal or a disability (Ariotti 1999; cf. Kapp 2011). Self-reported rates for diabetes are several times lower than clinically assessed rates.

Many Indigenous people regard only gross or highly visible conditions such as strokes, severe motor impairment, spinal cord injury, and amputation as disability (Gething 1995; Maher 1999). Conversely, in some communities, alcohol and drug dependence is seen as a disability as are some psychotic disorders. Definitions of disability vary widely across the highly diverse Indigenous communities. Standardized assessment tools (including the International Classification of Functioning and Disability [ICIDH-2]) and techniques are unreliable for many Indigenous people (Senior 2000; Holland and Persson 2011). 
As a consequence of these issues, the concept of preventable causes of impairment needs to encompass not only the full spectrum of social and health disadvantages experienced by Indigenous people but also their responses to such disadvantages. One particular issue is that of 'non-compliance', which needs to be understood as a reasonable response to insensitive and inappropriate behaviour by health professionals rather than as dereliction by 'incompetent' clients (Humphery, Weeramanthri, with Fritz 2001).

The third dimension of the ICIDH-2 was re-named 'participation' rather than the previous negative notion of handicap. This classification assesses opportunities available as well as the level of impairment per se. However, non-participation due to 'race', class, gender or religion is not recognized within the ICIDH-2. Yet in the urban Indigenous community researched by Senior (2000), many of those interviewed were much more likely to avoid social settings for fear of non-Indigenous attitudes and discrimination than on account of their physical disability. In stark contrast to the ICIDH-2, the National Aboriginal Community Controlled Health Organisation defines as 'Socio-somatic illness':

... those physical ailments, bodily disorders and psychological or mental conditions which impair the health of Aboriginal people and the well-being of Aboriginal communities resulting directly or indirectly from sociological disadvantage; economic deprivation; racism; assimilationist legislation, policies and practices; unemployment; lack of housing; dispossession; alienation from land; forced separation from parents, children, families and communities; and other traumas, which impinge and have impinged upon Aboriginal people since dispossession. (Cited in Australian Institute of Health \& Welfare \& Department of Health and Family Services 1998, 96)

If racism (and the fear of hostility) confines an Indigenous person with impairment to their home and family circle, what is the meaning of independence as a rehabilitation aim? If the mother of an Indigenous child will not seek help from the disability service she associates with the 'welfare' responsible for the removal of her older brother, who is disabled and by what?

What does participation mean in such circumstances? A similar issue concerns the impact of a lack of transport and location of services in preventing the access of many Indigenous people to disability and other health services (Smeaton 1998). If the unemployment rate for an Indigenous community is around $50 \%$, how does this impact on the right to 'meaningful work' of a disabled Indigenous person? For many Indigenous families, independence (especially for children) is seen as a cultural threat to the interdependence and cohesion of one's kin; a more valued ethic than the self-reliance on which much rehabilitation is predicated (for similar findings for minority communities in the USA, see Harry 2002; Devlieger, Albrecht, and Hertz 2007).

Cutting across these definitional problems is the issue of saliency. Non-immobilizing disabilities may not signify much in the context of many Indigenous people's lives, given other more immediate stressors and threats (Cunningham 2011). As Ian Hamm concluded:

The sheer number of acute health issues has effectively side lined those issues which are not life threatening. (Cited in Australian Institute of Health \& Welfare and Department of Health \& Family Services 1998, 5) 
Research has shown that the background of chronic poor health, bad nutrition, poverty, racism and marginalization experienced by many Indigenous people frequently subsumes specific conditions that would be identified as serious disabilities by health professionals (Smeaton 1998; Senior 2000; Meekosha 2011).

An impairment will be rated in terms of its social implications rather than according to metrics used for clinical assessment. In particular, its impact on a person's ability to socialize appropriately with kin and fulfil other cultural obligations may be the critical factor in identifying it as a disability (Anderson 1997). Some studies identified loss of cultural heritage and social networks as of greater concern than chronic diabetes, loss of sight and other disabling conditions (Gething 1995; Devitt and McMasters 1998; Ariotti 1999). The potential threat of unpredictable behaviour and aggressiveness may account for greater apprehension about a person's mental impairment compared with community reactions to physical disability (Senior 2000).

\section{Culturally appropriate or person-centred strategies}

Cultural competence approaches developed to enable non-Indigenous health professionals to work effectively with Indigenous communities often encourage static and essentialized notions of Indigenous culture (Downing and Kowal 2011). Beliefs, values and behaviours of Indigenous people are 'explained' in terms of deterministic cultural difference that ignores diversity and contradictions within Indigenous populations in ways that would never be applied to non-Indigenous middle-class people (Nelson 2007).

Such culturally deterministic approaches construct mechanistic checklists and intervention models that do not reflect critically on the taken-for-granted assumptions of orthodox professional practices (Hollinsworth 1992). Alternatively, strategies excuse non-Indigenous rehabilitation staff from taking responsibility to engage effectively by relying on the appointment of Indigenous intermediaries to provide the 'culturally-appropriate' liaison and support services required (Smeaton 1998; Kowal 2011).

Cultural myths can deny the support needs of Indigenous people with disabilities and their families. For example, the belief that, in a 'family-centred' culture, Indigenous people will always be taken care of by family members is almost universally repeated in the literature (Kendall and Marshall 2004). In fact the degree of family support for the frail aged or for those with disabilities is probably as variable as it is in any community, largely reflecting their individual standing and circumstances (Maher 1999; Senior 2000). Often those who bear the bulk of caring are themselves elderly, female and in need of support. In many Indigenous families, grandmothers with chronic ill-health and impairment care for most of the young children as well as those with health problems and other disabilities. This often leads to 'granny burnout' (Hammill 2001). Effective support services must avoid being shaped by romantic and inaccurate assessments of the needs of Indigenous families.

Approaches that incorporate holistic understandings and family-based strategies are more likely to provide effective support than narrow therapies that isolate a specific impairment. Policies that fund a raft of discrete services rather than a single organization may be regarded as progressive by many in the disability movement but may be contrary to a widespread Indigenous preference for an all-encompassing, 
community-controlled Aboriginal Health Service (Wolstenholme 1996; Smeaton 1998; Danelutti 2000).

The way forward requires equitable and long-term partnerships between Indigenous organizations and disability service providers that can overcome the many obstacles to Indigenous people's accessing of existing services (Kendall and Marshall 2004; McBain-Rigg and Veitch 2011). This engagement requires critical reflection on our own positionality, including 'white privilege', more than the acquisition of cultural knowledge or competence (Dean 2001; Bell 2006). These partnerships will see disability workers learning the long and sorry history of Australian racism alongside Indigenous clients and workers gaining deeper understandings of disabilities and options for managing them. The work of decolonizing Indigenous disability in Australia demands a focus on contesting the dominant social model of disability based on acknowledgement of our shared history of racism and recognition of the diversity of Indigenous perspectives on disability.

\section{References}

Aboriginal Disability Network NSW. n.d. http://www.adnnsw.org.au (accessed September 26, 2011).

Anderson, B. 1991. Imagined communities: Reflections of the origin and spread of nationalism. 2nd ed. London: Verso.

Anderson, I. 1997. The ethics of the allocation of health resources. In Race matters, ed. G. Cowlishaw and B. Morris, 191-209. Canberra: Aboriginal Studies Press.

Anderson, W. 2002. The cultivation of whiteness: Science, health and racial destiny in Australia. Carlton: Melbourne University Press.

Ariotti, L. 1999. Social construction of Anangu disability. Australian Journal of Rural Health 7, no. 4: 216-22.

Australian Health Ministers' Advisory Council. 2011. Aboriginal and Torres Strait Islander health performance framework report 2010. Canberra: AHMAC.

Australian Human Rights Commission. 2008. Preventing crime and promoting rights for Indigenous young people with cognitive disabilities and mental health issues. Sydney: AHRC.

Australian Institute of Health and Welfare and Department of Health and Family Services. 1998. Indigenous disability data - Current status and future prospects: Report on proceedings of the Canberra workshop, April 1998. Canberra: AIHW and DHFS.

Bashford, A., and M. Nugent. 2001. Leprosy and the management of race, sexuality and nation in tropical Australia. In Contagion: Historical and cultural studies, ed. A. Bashford and C. Hooker, 106-28. London: Routledge.

Bell, C. 2006. Introducing white disability studies: A modest proposal. In The disability reader, 2nd ed., ed. L. Davis, 275-82. London: Routledge.

Beresford, Q., and P. Omaji, eds. 1996. Rites of passage: Aboriginal youth, crime and justice. Fremantle: Fremantle Arts Centre Press.

Briscoe, G. 2003. Counting, health and identity: A history of Aboriginal health and demography in Western Australia and Queensland 1900-1940. Canberra: Aboriginal Studies Press.

Brock, P. 1993. Outback ghettoes: A history of Aboriginal institutionalisation and survival. Melbourne: Cambridge University Press.

Cocks, E., and D. Stehlik. 1996. History of services. In Disability: A guide for health professionals, ed. J. Annison, J. Jenkinson, and W.A. Sparrow, 9-32. South Melbourne: Thomas Nelson.

Commonwealth Government. 1937. Aboriginal welfare: Initial conference of Commonwealth and State Aboriginal authorities. Canberra: Government Printer.

Connell, R. 2011. Southern bodies and disability: Re-thinking concepts. Third World Quarterly 32, no. 8: $1369-81$.

Cox, L. 2007. Fear, trust and Aborigines: The historical experience of state institutions and current encounters in the health system. Health and History 9, no. 2: 70-92. 
Cunningham, J. 2011. Socioeconomic disparities in self-reported arthritis for Indigenous and non-Indigenous Australians aged 18-64. International Journal of Public Health 56: 295-304.

Danuletti, M. 2000. Meeting the needs of Koorie people with a disability: Developing and implementing strategies for improving service equity and access. Melbourne: Department of Human Services.

Davidson, W.S. 1978. Havens of refuge: A history of leprosy in Western Australia. Perth: University of Western Australia Press.

Dean, R. 2001. The myth of cross-cultural competence. Families in Society 82, no. 6: 623-30.

Devitt, J., and A. McMasters. 1998. Living on medicine: A cultural study of end-stage renal disease among Aboriginal people. Alice Springs: Institute of Aboriginal Development Press.

Devlieger, P., G. Albrecht, and M. Hertz. 2007. The production of a disability culture among young African-American men. Social Science \& Medicine 64: 1948-59.

Downing, R., and E. Kowal. 2011. A postcolonial analysis of Indigenous cultural awareness training for health workers. Health Sociology Review 20, no. 1: 5-15.

Eckermann, K. 2000. Lock hospitals, prisons and Indigenous people, Queensland and Western Australia, 1906-1998. In Settlement: A history of Australian Indigenous housing, ed. P. Read, 209-20. Canberra: Aboriginal Studies Press.

Evans, R. 1976. The hidden colonists: Deviance and social control in colonial Queensland. In Social policy in Australia, ed. J. Roe, 74-100. Stanmore: Cassell.

Gething, L. 1994. Across the divide: Distance, diversity and disability. Volume 11 Aboriginality and disability. Sydney: Community Disability and Ageing Program, University of Sydney.

Gething, L. 1995. A case study of Australian Aboriginal people with disabilities. Australian Disability Review 2: 77-88.

Goggin, G., and C. Newell. 2005. Disability in Australia: Exposing a social apartheid. Sydney: UNSW Press.

Goodwin, C. 1964. Evolutionary theory in Australian social thought. Journal of the History of Ideas 25: 393-416.

Graham, S. 2006. Why me? Stories from the stolen generations. Adelaide: Nunkuwarrin Yunti of South Australia.

Griffis, D. 2012. Disability in Indigenous communities: Addressing the disadvantage. http:// www.abc.net.au/rampup/articles/2012/04/20/3481394.htm (accessed February 3, 2012).

Groce, N., and J. Marks. 2000. The Great Ape Project and disability rights: Ominous undercurrents of eugenics in action. American Anthropologist 102, no. 4: 818-22.

Haebich, A. 2000. Broken circles: Fragmenting Indigenous families 1800-2000. Fremantle: Fremantle Arts Centre Press.

Hammill, J. 2001. Granny rights: Combatting the granny burnout syndrome among Australian Indigenous communities. Development 44, no. 2: 69-74.

Harry, B. 2002. Trends and issues in serving culturally diverse families of children with disabilities. Journal of Special Education 36, no. 3: 131-40.

Hasnain, R., P. Sotnik, and C. Ghiloni. 2003. Person-centered planning: A gateway to improving vocational rehabilitation services for culturally diverse individuals with disabilities. The Journal of Rehabilitation 69, no. 3: 10-7.

Holland, S., and P. Persson. 2011. Intellectual disability in the Victorian prison system: Characteristics of prisoners with an intellectual disability released from prison in 2003-2006. Psychology, Crime \& Law 17, no. 1: 25-41.

Hollinsworth, D. 1992. Cultural awareness training, racism awareness training, or antiracism? Strategies for combating Institutional racism. Journal of Intercultural Studies 13, no. 2: $37-52$.

Hollinsworth, D. 2006. Race and racism in Australia. 3rd ed. South Melbourne: Cengage.

Human Rights and Equal Opportunity Commission. 1997. Bringing them home. Sydney: Commonwealth of Australia.

Humphery, K., T. Weeramanthri, with J. Fritz. 2001. Forgetting compliance. Aboriginal health and medical culture. Darwin: Northern Territory University Press.

Hunter, E. 1993. Aboriginal health and history: Power and prejudice in remote Australia. Melbourne: Cambridge University Press. 
Jakubowicz, A., and H. Meekosha. 2002. Bodies in motion: Critical issues between disability studies and multicultural studies. Journal of Intercultural Studies 23, no. 3: 237-52.

Jebb, M. 1984. The lock hospitals experiment: Europeans, Aborigines and venereal disease. Journal of Studies in Western Australian History 8: 68-87.

Kapp, S. 2011. Navajo and autism: The beauty of harmony. Disability and Society 26, no. 5: 583-95.

Kendall, E., and C. Marshall. 2004. Factors that prevent equitable access to rehabilitation for Aboriginal Australians with disabilities: The need for culturally safe rehabilitation. Rehabilitation Psychology 49, no. 1: 5-13.

Kowal, E. 2011. The stigma of white privilege. Cultural Studies 25, no. 3: 313-33.

Kunitz, S. 1994. Disease and diversity: The European impact on the health of non-Europeans. New York: Oxford University Press.

Lester, Y. 2000. Yami. Alice Springs: Jukurrpa Books.

Maher, P. 1999. Disability in the Australian Aboriginal population. Australian Journal of Primary Health - Interchange 5, no. 3: 10-20.

Markus, A. 1990. Governing savages. Sydney: Allen and Unwin.

Martin, S. 2011. Starvation fears in Aboriginal lands. The Advertiser, September 1: 1.

McBain-Rigg, K., and C. Veitch. 2011. Cultural barriers to health care for Aboriginal and Torres Strait Islanders in Mount Isa. Australian Journal of Rural Health 19: 70-4.

McGregor, R. 1997. Imagined destinies: Aboriginal Australians and the doomed race theory, 1880-1939. Melbourne: Melbourne University Press.

McGregor, R. 2000. 'Breed out the colour': Reproductive management for White Australia. In 'A race for a place' eugenics, Darwinism and social thought and practice in Australia, ed. M. Crotty, J. Germov, and G. Rodwell, 61-70. Callaghan: University of Newcastle.

Meekosha, H. 2006. What the hell are you? An intercategorical analysis of race, ethnicity, gender and disability in the Australian body politic. Scandinavian Journal of Disability Research 8, nos 2-3: 161-76.

Meekosha, H. 2011. Decolonising disability: Thinking and acting globally. Disability \& Society 26, no. 6: 667-82.

Meekosha, H., and L. Dowse. 1997. Enabling citizenship: Gender, disability and citizenship in Australia. Feminist Review 57: 49-72.

Meekosha, H., and K. Soldatic. 2011. Human rights and the Global South: The case of disability. Third World Quarterly 32, no. 8: 1383-97.

Ministerial Council for ATSI Affairs. 2006. Bringing them home: A report on the economic and social characteristics of those impacted on by past policies of forcible removal of children, June, Canberra.

Moreton-Robinson, A. 2000. Talkin' up the white woman: Indigenous women and white feminism. St Lucia: University of Queensland Press.

Nelson, A. 2007. Seeing white: A critical exploration of occupational therapy with Indigenous Australian people. Occupational Therapy International 14, no. 4: 237-55.

Nelson, A. 2009. Learning from the past, looking to the future: Exploring our place with Indigenous Australians. Australian Occupational Therapy Journal 56: 97-102.

Productivity Commission. 2011. Overcoming Indigenous disadvantage: Key indicators 2011. Canberra, Productivity Commission (Steering Committee for the Review of Government Service Provision). http://www.pc.gov.au/gsp/reports/indigenous/key-indicators-2011 (accessed October 26, 2011).

Rowley, C. 1970. The destruction of Aboriginal society. Canberra: Australian National University Press.

Salmon, A. 2004. 'It takes a community': Constructing Aboriginal mothers and children with FAS/FAE as objects of moral panic in/through a FAS/FAE prevention policy. Journal of the Association for Research on Mothering 6, no. 1: 112-23.

Salmon, A. 2007. Dis/abling states, dis/abling citizenship: Young Aboriginal mothers and the medicalization of fetal alcohol syndrome. Journal of Critical Education, Policy Studies 5, no. 2. http://www.jceps.com/?pageID=article8articleID=103 (accessed May 5, 2012).

Senior, K. 2000. Testing the ICIDH-2 with Indigenous Australians: Results of field work in two Aboriginal communities in the Northern Territory. Canberra: Australian Institute of Health and Welfare. 
Smeaton, T. 1998. Family dreaming: Support programs for Aboriginal and Torres Strait Islander people with disabilities. Sydney: Ageing and Disability Department.

Soldatic, K., and L. Fiske. 2009. Bodies 'locked up': Intersections of disability and race in Australian immigration. Disability \& Society 24, no. 3: 289-301.

Stepan, N. 1991. 'The hour of eugenics': Race, gender, and nation in Latin America. Ithaca, NY: Cornell University Press.

Wolstenholme, R. 1996. Caring for Aboriginal people with disabilities. Australian Disability Review 3: 3-14. 